\title{
Abrir a fábula: Questões da política do passado em Moçambique
}

Opening the Fable: Questions of the Politics of the Past in Mozambique

Ouvrir la fable: Questions de politique du passé au Mozambique

João Paulo Borges Coelho

\section{OpenEdition}

\section{Journals}

Edição electrónica

URL: http://journals.openedition.org/rccs/5926

DOI: $10.4000 /$ rccs. 5926

ISSN: 2182-7435

\section{Editora}

Centro de Estudos Sociais da Universidade de Coimbra

Edição impressa

Data de publição: 1 Maio 2015

Paginação: 153-166

ISSN: 0254-1106

Refêrencia eletrónica

João Paulo Borges Coelho, "Abrir a fábula: Questões da política do passado em Moçambique »,

Revista Crítica de Ciências Sociais [Online], 106 | 2015, colocado online no dia 28 abril 2015, criado a 30 abril 2019. URL : http://journals.openedition.org/rccs/5926 ; DOI : 10.4000/rccs.5926 


\section{JOÃO PAULO BORGES COELHO}

\section{Abrir a fábula: Questões da política do passado em Moçambique*}

Este texto discute o uso do passado na actual vida política em Moçambique. Em particular, detém-se na narrativa fundadora da nação moçambicana (formulada como história de conteúdo moral, ou fábula), questionando aspectos como o da sua relação com outras memórias e a sua natureza oral. Desta última, resulta, por um lado, uma capacidade de adaptação às alterações circunstanciais do presente, e por outro um grande poder dos detentores da narrativa - as testemunhas. Discute também as relações necessariamente de tensão entre a memória política e a historiografia. No fundo, pergunta-se em que medida esta narrativa não se constitui como instrumento poderoso de diferenciação social e privilégio no actual quadro de luta pela democracia.

Palavras-chave: historiografia; identidade; luta política; memória coletiva; Moçambique.

O nosso conhecimento do passado é inevitavelmente incerto, descontínuo, lacunar: baseado numa massa de fragmentos e de ruínas. Carlo Ginzburg (2007: 40)

\section{Introdução}

Num texto a que deu o título de "Descrição e citação", o historiador italiano Carlo Ginzburg (2007: 17-40) discute como foi construída ao longo dos tempos, em particular na narrativa ocidental, a ideia de passado e a maneira de o "contar". Mostra como os antigos prezavam o esforço de relatar a coisa ausente com tal vividez que a encenação do orador tornava quase palpável um objecto ausente. Começou por ser esta a ars historica, feita de oralidade,

\footnotetext{
* Este artigo baseia-se em, e retoma em grande medida, um texto anterior com o título "Memory, History, Fiction: A Note on the Politics of the Past in Mozambique", apresentado na École des Hautes Études en Sciences Sociales (EHESS), por ocasião das celebrações dos cinquenta anos das independências africanas (Paris, 21-22 de Outubro de 2010). O presente texto é também resultado do projecto PTDC/AFR/121404/2010 - FCOMP-01-0124-FEDER-019531.
} 
teatro e ficção, e em que paulatinamente vamos sentindo crescer uma certa tensão entre as virtudes do estilo (incluindo a retórica) e algo mais que poderíamos aqui situar como evidência. É desta tensão entre duas virtudes, entre a arte da retórica e a erudição dos anais (enquanto relatos de evidências secos e sem estilo) que vai emergindo a maturidade da historiografia. No caminho, foram-se adquirindo pontes entre estas duas grandes regiões, entre elas a "citação", que Ginzburg diz ser um modo de sublinhar "que o passado nos é acessível apenas de modo indirecto, mediado" (2007:37). Enquanto a origem da retórica se situa na oralidade e na gestualidade, a citação remete para a evidência, que no nosso tempo é representada em grande medida pelo documento ou pelo objecto documental.

É neste campo (e não em outros, como por exemplo a competitividade ou legitimidade de narrativas com agências diferentes) que quero situar a minha apresentação. Nomeadamente, na discussão de algumas questões concretas relacionadas com condições sociais e políticas de produção do trabalho historiográfico. E, em lugar de reduzir essas condições a meros obstáculos no caminho da produção da história, integrá-las como elementos que obrigam ao aprofundamento do debate epistemológico.

Chego pois ao tema desta minha apresentação a partir de uma questão muito particular - esta e não outra - que é a da possibilidade da narrativa historiográfica num meio concreto. Penso que no decorrer da tentativa de resposta a essa questão ficará também dita alguma coisa sobre a natureza dessa narrativa, quer no que toca aos seus próprios sujeitos quer na relação que estabelece com outras narrativas de memória.

\section{Origem da fábula}

Como bem sabemos, o processo de independência de Moçambique, tal como o das principais colónias portuguesas, teve características que o distinguiram dos restantes territórios africanos: foi tardio e envolveu uma luta armada. Para alguns, a natureza do colonialismo português (ou o tipo de luta levado a cabo para o derrubar) pode ter estado por trás da radicalização do processo de emancipação de Moçambique, uma radicalização que transformou o sentido da independência e fez dela muito mais que uma mera substituição de elites políticas, de facto uma revolução política e social. ${ }^{1}$

Os principais instrumentos para implementar tal revolução, uma vez conquistada a independência, foram o partido Frelimo (a Frente que lutou pela independência foi transformada em 1977 em partido marxista-leninista)

\footnotetext{
${ }_{1}$ Alguns autores encontram uma correlação entre a natureza do colonialismo e a radicalização da independência. Ver, por exemplo, Ki-zerbo et al. (1993).
} 
e uma ideia de passado construída em torno da luta de libertação como verdadeira fonte dessa revolução, uma ideia baseada na experiência, ou vivência, de um processo que criou a unidade entre todos os moçambicanos e estabeleceu as bases da derrota do colonialismo português.

Enquanto prática, a luta de libertação permitiu iniciar a revolução nas zonas libertadas e imaginar o futuro do país logo que aquela experiência nele fosse aplicada. A memória da luta de libertação e da experiência revolucionária das zonas libertadas desempenhou assim um papel central na política e na vida após a independência, não só como um passado que reverberava no presente mas também como farol e referência na caminhada para o futuro. Como procurei mostrar noutro lugar (Coelho, 2005; 2007; 2013), a luta armada cumpriu esse papel não só ao ser o acto que permitiu aos moçambicanos surgir com uma identidade nacional, mas também na medida em que forneceu a base da legitimidade das políticas governamentais após a independência, e uma espécie de carte blanche para as decisões políticas e de desenvolvimento, no sentido em que essas decisões, tomadas pelos mesmos protagonistas que haviam vencido a luta, eram apresentadas como uma espécie de continuação das práticas adoptadas nas antigas zonas libertadas. Incluído nessa lógica de continuidade estava o apelo à manutenção da unidade adoptada durante a luta, o que se por um lado criava uma coesão necessária para enfrentar a hostilidade da região da África Austral da segunda metade da década de 1970, por outro também desempenhava importante papel ilegitimando qualquer tipo de contestação política, naturalmente identificada com uma tentativa de ruptura dessa linha de continuidade.

Em suma, a luta de libertação era uma ideia do passado que veio a formar o núcleo e a substância do processo de construção da nação, e a determinar o desenvolvimento político nos quinze anos que se seguiram à declaração da independência, em 1975. Foi em torno da luta de libertação que a memória política se estruturou. ${ }^{2}$

Evidentemente, a ideia de criar uma "reverberação controlada" de acontecimentos passados no presente não é nova. De facto, o que nós consideramos como passado é também uma visão que olhos e motivos actuais têm dele - olhos e motivos que se concretizam numa narrativa. Lembrar, como nos avisa Todorov (2004), é sempre um processo selectivo guiado

\footnotetext{
2 Distingo "memória política" de "memória colectiva". Resumidamente, a "memória política" é controlada pelas autoridades, que tentam fazer dela uma "memória colectiva". É mais estruturada e activa, enquanto a memória colectiva é passiva e funciona como uma espécie de sedimentação que ocorre ao longo do tempo.
} 
por critérios estabelecidos no presente. ${ }^{3}$ E, claro, todos os Estados desenvolvem mecanismos próprios para tentar controlar e utilizar o passado de forma a criar uma memória política que favoreça os seus desígnios, memória que se espera vir a ser transformada, no futuro, em memória colectiva ou histórica, sendo que a primeira é partilhada por todos no presente e a segunda capaz de sobreviver na longa duração.

Um recurso particular de memória política consiste na promoção de histórias nacionais ou oficiais que, nas palavras de Beatriz Sarlo, são normalmente feitas de "um panteão de heróis, um grupo de excluídos e réprobos, uma linha de desenvolvimento unitário conduzindo até ao presente" (2007: 13-14). Histórias que são simples e claras, com um forte acento nacionalista, e que circulam amplamente nas escolas ou nos média, por meio de processos já amplamente explicados desde a velha noção marxista de aparelhos ideológicos do Estado.

Moçambique também teve a sua luta de libertação codificada nos mesmos moldes como grande narrativa, com a estrutura simples de uma fábula ${ }^{4}$ começando simbolicamente com uma agressão colonial (o massacre de Mueda, que corresponde a outros fenómenos idênticos como o massacre de Pidjiguiti de 1959 para a Guiné-Bissau, ou a vaga de repressão que se seguiu ao assalto ao Presídio de Luanda de 1961 para Angola, Viriato em Portugal, etc.), seguida do "primeiro tiro" disparado pelos guerrilheiros contra os colonialistas, e desenrolando-se como uma história heróica na qual o movimento se foi libertando da carga impura dos reaccionários (o II Congresso da Frelimo) e foi adquirindo uma crescente pureza revolucionária. A história é escorada por uma série de oposições binárias (colonialismo versus revolução, reaccionários versus revolucionários, civis versus militares, rural versus urbano, etc.) e claramente é a sua simplicidade que lhe confere uma tremenda eficácia.

\section{A natureza oral da fábula}

O que parece muito interessante, e num certo sentido invulgar, é que, apesar da sua centralidade para a vida do país, esta grande narrativa permaneceu

\footnotetext{
3 Todorov escreve que "[...] a memória não se opõe radicalmente ao esquecimento. Os dois termos contrastantes são o apagamento (o esquecimento) e a conservação; a memória é, sempre e necessariamente, uma interação destes dois elementos. A restituição integral do passado é impossível [...]. A memória é, necessariamente, uma selecção" (2004: 14) [tradução do editor].

${ }^{4}$ Defino uma utilização precisa de fábula (do latim fari, falar, e do grego phaó, dizer - portanto com uma matriz ligada à oralidade), como narração, conto, história com um fundo moral. $\mathrm{Na}$ Grécia Antiga era um discurso da imaginação que retratava uma verdade e tinha o propósito de entreter e aconselhar; La Fontaine, talvez o seu mais famoso cultor, definia-a como pequena narrativa que, sob o véu da ficção, guarda uma moralidade.
} 
verbal, ancorada em palavras apenas proferidas. Em trinta e cinco anos de independência nunca foi feita uma tentativa decisiva para a escrever, para a registar na forma escrita. Se excluirmos os discursos fragmentários de Samora Machel ocasionalmente publicados pela Frelimo e pelos canais de informação e propaganda do Estado, ou pelos jornais por ocasião de datas celebrativas, não existe uma história oficial escrita da saga da libertação. De que maneira entender este fenómeno singular?

Evidentemente que não se pode falar aqui num pretenso mecanismo de tradição oral culturalmente enraizado, dado que a luta de libertação é um fenómeno que rompe precisamente com a tradição e de certa forma inaugura a modernidade.

Penso que se deve procurar mais do que uma razão. Em primeiro lugar e desde logo, manter a história verbal era talvez a melhor maneira de a salvaguardar de desvios a um cânone cujos contornos não estavam inteiramente estabelecidos (e a ausência de desvios, por seu turno, contribuía para reforçar a coesão da fábula). Por outro lado, se olharmos de um ângulo diferente, o facto de ser verbal conferia à narrativa maior flexibilidade e capacidade de adaptação às mudanças de contexto; por outras palavras, tal como foi dito, maior eficácia.

\section{Destruição e construção da experiência}

É importante ter em conta que a luta de libertação, baseada na Tanzânia, foi-se estabelecendo progressivamente nas províncias setentrionais, onde criou zonas libertadas, mas não chegou directamente a extensas zonas do país, incluindo as cidades mais importantes (e a capital Maputo) e a região meridional em geral. Nestas zonas "não-afectadas" a população, embora destituída da experiência da luta armada, certamente que experimentou outros tipos de vivências coloniais, delas alimentando memórias privadas e comunitárias. Todavia, após a independência, e apesar das palavras da velha canção revolucionária ("não vamos esquecer o tempo que passou"), as memórias públicas que forneceram a matéria-prima do futuro vieram não dessas experiências do resto do país mas das zonas libertadas.

Alego pois que, num processo que precisa sem dúvida de ser melhor conhecido, a nova memória política independente foi como que "importada" das zonas libertadas, muito mais que construída sobre as cinzas da velha memória política e social da era colonial. ${ }^{5}$ Colocando as coisas algo

\footnotetext{
5 Evidentemente que seria descabido inferir aqui uma natureza "externa" da Frelimo, aliás formada em grande medida por moçambicanos do extremo Sul, que abandonaram o país para se juntar às forças nacionalistas. Pretende-se apenas descrever a mecânica de funcionamento ao nível da experiência e da memória dessa experiência.
} 
radicalmente, foi como se no novo país independente não houvesse espaço para o passado mas apenas para o devir, e tudo, inclusivamente o passado, fosse construído a partir do futuro. Gradualmente, a nova atitude deixava de ser "fazer diferente do colonialismo" para passar a ser "fazer igual às zonas libertadas". Era como se o mundo colonial fosse identificado com o tempo do mal, de onde nem sequer a experiência podia ser colhida. Neste sentido, reitero, a independência foi a negação da experiência de muitos em favor da ilusão da escrita do presente numa tabula rasa. ${ }^{6}$ Por outro lado, a erradicação da experiência colonial (que também era, obviamente, uma experiência moçambicana), salvaguardava a experiência da luta armada do confronto com outras experiências, e portanto de uma relativização que enfraqueceria o seu carácter absoluto. Garantia assim o estatuto da luta armada como única experiência. ${ }^{7}$

\section{O papel da testemunha}

Um outro aspecto fundamental da ausência de um texto canónico escrito foi que isso reforçou o papel daqueles que testemunharam a luta de libertação, aqueles que participaram nela e consequentemente podiam reclamar ser portadores daquela experiência, a única verdadeiramente importante. Tal excluía evidentemente um grande número de moçambicanos destituídos da experiência da luta, como vimos, mas também muitos que tiveram tal experiência mas não estavam em situação de a enunciar na qualidade de testemunhas.

Explico-me. Nem todos os combatentes da guerrilha percorreram o itinerário que eleva o mero protagonista do acontecimento à condição de testemunha. Tornar-se testemunha pressupõe ter conquistado e mantido, na nova ordem que se seguiu à declaração da independência, uma voz capaz de contar a história. E, uma vez que desde a independência não foi levado a cabo qualquer empreendimento sistemático para registar com um método

\footnotetext{
${ }^{6}$ Este aspecto pode evidentemente ser discutido em mais do que um contexto, e foi reforçado, em termos muito concretos, pela questão relativamente inexplorada do êxodo português na altura da independência, que para o país também implicou uma menos simbólica e muito concreta negação da experiência (privação de conhecimento técnico para conduzir serviços e a economia em geral, etc.). Este argumento explica em parte, por exemplo, por que razão o odiado esquema colonial de reordenamento populacional dos aldeamentos foi candidamente repetido uns meros três anos após a independência, mesmo se com objectivos obviamente distintos. Ou - um outro exemplo o receio das novas autoridades, após a independência, do protagonismo das tropas africanas que o colonialismo deixou para trás, algumas delas altamente especializadas - por outras palavras, dotadas da experiência do mal. Tudo isto inviabiliza a ideia da sociedade como uma folha em branco onde, sem qualquer compromisso, pode começar a escrever-se um novo texto.

${ }^{7}$ Poderíamos encarar os campos de reeducação criados após a independência como parte do mesmo princípio que visava que as pessoas se livrassem da velha experiência (esquecer os maus hábitos) e adquirissem a experiência nova.
} 
adequado o testemunho dos guerrilheiros e outros participantes na luta armada, aqueles que conquistaram uma voz capaz de contar a história foram os que entraram nas cidades e vieram a desempenhar cargos de relevo nas estruturas da Frelimo e do Estado. A esses há que acrescentar, no período de transição entre o golpe militar do 25 de Abril de 1974 e a independência, alguns revolucionários com papéis políticos e sociais de relevo mas destituídos da experiência da luta, que foram consequentemente enviados para os campos da Frelimo na Tanzânia a fim de a adquirir simbolicamente.

O meu argumento, aqui, não visa inferir nenhum tipo de divisão social ou privilégio, o que nos levaria por outra linha de raciocínio, mas simplesmente mostrar que a acentuada redução no número de vozes capazes de contar a história está inquestionavelmente por detrás da grande coesão desta, uma coesão que foi reforçada pela disciplina militarizada que então vigorava.

O estatuto de testemunha (o revolucionário, aquele dotado da correcta experiência e de voz capaz de a enunciar) conferiu um capital importante àqueles que a ele tiveram direito após a independência, em mais do que uma dimensão. Em particular, foi importante de um ponto de vista moral (compreensivelmente, ter participado na libertação do país constituía uma experiência da mais elevada qualidade possível), mas também politicamente (tornando pública tal qualidade) e até em termos materiais. ${ }^{8}$ E, evidentemente, onde e sempre que não estavam disponíveis fontes alternativas, a testemunha tornava-se a única fonte da narração, o que aumentava enormemente a força da sua voz.

Em alguns aspectos, e apesar das diferenças óbvias e mesmo do contraste, é possível encontrar aqui ressonâncias da testemunha tal como é discutida no contexto oposto de memórias de acontecimentos passados extremos, tais como o holocausto ou as ditaduras da América do Sul na década de 1970, em particular quando a testemunha se torna a única fonte. ${ }^{9}$

Evidentemente, nesses casos negativos extremos a testemunha transporta consigo a experiência de um passado maléfico, enquanto aqui essa experiência (associada ao ambiente colonial) é progressivamente removida e substituída por uma categoria oposta, nobre e positiva, e ligada ao futuro. Se nos casos do holocausto e das juntas latino-americanas a questão está em contar o sucedido (no primeiro, por vezes em transmitir a experiência dos que deixaram de ser capazes de o fazer, ou mesmo ser impossível viver com

\footnotetext{
${ }^{8}$ Por exemplo, além de privilégios mais informais e de acesso e oportunidades de emprego, etc., o tempo passado na luta conta duas vezes para a reforma do serviço público ou permite que os descendentes, na qualidade de "filhos de ex-combatentes", tenham acesso ao ensino superior sem passar pelo sistema de selecção aplicado ao cidadão comum.

9 Seguindo a linha argumentativa de Sarlo (2007: 21).
} 
essa experiência), aqui, num contexto em que o orgulho substitui o trauma, a vergonha ou a dor, a finalidade é afirmar a memória de uma experiência comum de forma a reforçar a coesão da versão colectiva.

Como atrás foi dito, quando a experiência colectiva se transforma de experiência comum de muitos em experiência "futura" de todos, por outras palavras, quando a versão ganha voz para se tornar em grande narrativa ou memória política com alcance nacional, passa a exercer grande pressão, não se limitando às memórias subalternas (individuais, comunitárias, etc.). Podemos encontrar vários exemplos de ruído na convivência entre as memórias subalternas e a memória política. Um deles é quando antigos combatentes involuntariamente contradizem a narrativa canónica, nomeadamente quando assumem com alguma candura ter morto inimigos fora de situações de combate, ou quando afirmam que os guerrilheiros zimbabuanos não passavam de poltrões com sede de poder. Quando o confronto é directo, a memória subalterna tende no entanto a desaparecer, ou pelo menos a silenciar-se. ${ }^{10}$

\section{A historiografia e a fábula}

Por outro lado, na sua qualidade de "narrativa fechada", a fábula convive dificilmente com outros mecanismos sociais de lidar com o passado, nomeadamente a história enquanto disciplina académica, os arquivos, ou ainda várias formas de expressão artística, incluindo a literatura de ficção.

Há um número de razões pelas quais a memória política e a historiografia não são bons vizinhos. Além de ameaçar escrever a narrativa, expondo-a assim a riscos imprevisíveis, esta última é uma actividade que pesquisa os arquivos, entrevista pessoas, espreita todo o tipo de fontes e não se submete necessariamente ao que a primeira define como interesse público. Mesmo se "colaborativa", a única garantia da historiografia é de trazer complexidade e contradição interna a um corpo cuja eficiência depende precisamente do oposto: simplicidade. Znepolski escreve que "a memória [política] tende a eliminar testemunhas concorrentes, tende a enfraquecer os seus argumentos e a criar as condições necessárias para impor a memória 'dos seus', a 'memória partilhada"” (2001: 82).

\footnotetext{
${ }^{10}$ Um exemplo particularmente interessante de confronto de narrativas de memória, de contornos ainda pouco esclarecidos, é o das chamadas "narrativas de sofrimento". A "narrativa de sofrimento" consistia numa cerimónia em que o recém-entrado na estrutura partidária (ou da guerrilha?) narrava junto da multidão de companheiros a sua experiência de sofrimento sob o colonialismo, que evidentemente justificava a sua decisão de se juntar à luta anticolonial. Simbolicamente, "entregava" a sua experiência ao grupo, num processo em que, penso, se procedia colectivamente à separação dos elementos dessas experiências individuais que deviam ser descartados e os que cabiam na experiência colectiva e a alimentavam. Desconheço no entanto, para além de menções indirectas e circunstanciais, qualquer referência sistemática sobre este fenómeno.
} 
Esta é a razão principal pela qual, apesar do défice de conhecimento histórico herdado dos tempos coloniais, a história contemporânea não mereceu atenção especial por parte das autoridades após a independência. Por outro lado, muito raramente a historiografia criou ou defendeu o seu próprio campo, distinto do campo político que nutria a grande narrativa. Uma já famosa excepção, muito particular, foi a do artigo de Aquino de Bragança e Jacques Depelchin (1986), ${ }^{11}$ no qual a visão triunfalista do passado que figura na grande narrativa era severamente criticada por fornecer um quadro desprovido de problemas e cheio de certezas, em que o inimigo se apresentava "congelado" e incapaz de transformação ao longo da luta, enquanto o movimento nacionalista tinha a vitória por destino natural. Por outras palavras, eles exigiam que fosse restituído o espaço da história, dos seus métodos e debate, algo que a grande narrativa inviabilizara.

\section{A escrita da fábula e o início do seu envelhecimento}

O Acordo de Paz de 1992 assinala uma profunda mudança no país. O acordo acabou com a guerra e permitiu a realização de uma transição política do socialismo para uma nova ordem democrática. Neste novo contexto, seriam de esperar grandes mudanças relativamente ao papel do passado. Em particular, seria de esperar uma mudança que implicasse a substituição da grande narrativa pela democracia enquanto referencial da construção nacional e da nova ordem, num contexto em que, embora permanecendo como "explicação da origem", a luta armada perderia alguma carga de dramaticidade. Por detrás de tal expectativa estavam algumas razões, nomeadamente a sobreposição de um novo passado tornado muito complexo pela guerra civil, o facto de a geração de antigos combatentes (a "geração das testemunhas") estar a envelhecer rapidamente e a ser inexoravelmente substituída por uma nova geração que emergiu após a independência (e portanto sem experiência da luta armada), e acima de tudo a cultura instilada pelo neoliberalismo, em que a incidência no presente é tão intensa que pouco espaço deixa para o passado ou o futuro. ${ }^{12}$

Esta expectativa só em parte se revelou ajustada. Adoptou-se a democracia formal mesmo com fragilidades importantes, nomeadamente em aspectos como a separação de poderes ou a consolidação da pluralidade política. A competição ganhou o espaço da ética revolucionária enquanto conteúdo da nova narrativa. O cosmopolitismo cresceu. E todavia, de forma algo

\footnotetext{
${ }^{11}$ Também publicado em inglês como "From the Idealization of Frelimo to the Understanding of the Recent History of Mozambique", African Journal of Political Economy, I(1), 162-180.

12 Sarlo (2007: 30) fala da crise de autoridade do passado sobre o presente, no nosso tempo. Num registo próximo, Agamben (2008: 30) diz que a humanidade perdeu experiência no sentido em que hoje em dia ninguém aceitaria a autoridade baseada na experiência.
} 
surpreendente, a grande narrativa da luta de libertação não perdeu centralidade na sociedade. Pelo contrário, tal centralidade foi de certa forma reforçada nas mesmas linhas que haviam prevalecido no ciclo socialista anterior. Os arquivos permaneceram fechados e os sinais são agora de que esta situação não se alterará por muito tempo. ${ }^{13}$

Mas eis que recentemente algo de realmente inesperado começou a acontecer. Muitos antigos combatentes, muitas testemunhas começaram a publicar livros de memórias. Primeiro um ou dois, e depois muitos mais, alguns tentando experiências quasi-ficcionais, outros anunciando memórias ou "a verdade". Que pensar de tudo isto? Em primeiro lugar, que se trata de um fenómeno que pode ser entendido a partir de mais que um ângulo. Pode ser a vontade de deixar rasto de uma geração que agora se retira da cena política. Pode também ser uma espécie de certificado de pertença ou de lealdade a um partido tornado algo crispado no ambiente democrático, e vendo no reforço da sua coesão a forma de enfrentar os tempos actuais. Pode ser portanto falar do passado como forma de garantir o presente. Finalmente, pode haver ainda traços de uma ilusão segundo a qual, da mesma forma que condenou o terrorismo de Estado na América do Sul dos anos 1970-80, ou o apartheid na África do Sul, a testemunha, ao perpetuar por escrito esse registo, pretende resgatar a fábula dos perigos actuais, sacralizando-a.

Em qualquer dos casos, trata-se de um fenómeno perturbador. Além de a tentar sacralizar, a testemunha escreve a narrativa fragmentariamente, ameaçando produzir um quadro pouco coerente do todo. Além disso, a palavra escrita ajuda a fixar a história, ancora-a a um tempo concreto, transformando assim profundamente a sua natureza. A partir de agora a narrativa começará a ter uma idade. A partir de agora a narrativa começará a envelhecer.

Esses sinais começam a ser notados tanto no corpo da narrativa como no contexto em que ela respira. Relativamente ao primeiro aspecto, há elementos-chave que começam a ser questionados, como foi o caso das dúvidas recentemente colocadas (e provenientes do interior, de uma testemunha), sobre quem disparou o primeiro tiro contra o colonialismo, desencadeando

\footnotetext{
${ }_{13}$ Assim acontece apesar do facto de existirem argumentos fortes, legais e éticos, em favor da abertura dos arquivos. O argumento legal baseia-se no Decreto n. ${ }^{\circ} 33$ de 26 de Outubro de 1992, sobre o Sistema Nacional de Arquivos, que afirma que toda a documentação se torna histórica decorridos trinta anos, e nessa qualidade deve estar acessível ao público a não ser que a sua reserva ou confidencialidade sejam explicitamente declaradas, o que torna histórica a documentação sobre a luta armada, devendo nessa qualidade estar acessível ao público. Quanto ao argumento ético, ele tem a ver com o facto de que a documentação nacionalista foi produzida por uma frente de libertação nacional no contexto de uma guerra de libertação nacional, e consequentemente é nacional e pública no sentido mais profundo. Apesar disso, a documentação referida permanece fechada e sob custódia de um partido político, a Frelimo.
} 
um debate sobre um dos elementos mais simbólicos e nucleares da fábula, elemento que seria impensável desafiar alguns anos atrás. Relativamente ao contexto, também recentemente o secretário-geral da Frelimo afirmou aos média que o Museu da Revolução, o espaço por natureza da saga, pertencia, era propriedade, não do povo moçambicano mas do partido Frelimo. Tudo isto revela que a erosão ataca o corpo e o sentido do texto.

E tudo isto nos coloca numa encruzilhada fundamental. O que acontecerá a seguir?

Em primeiro lugar, parece-me óbvio que as coisas não poderão permanecer assim para sempre. Decorridos cinquenta anos desde o início da luta armada, as testemunhas começam a desaparecer. Mais do que isso, há sinais de que, ao escreverem as suas memórias e versões, essas mesmas testemunhas erodem seriamente a narrativa pelo simples facto de a encapsularem num texto escrito, criando várias contradições entre os seus elementos estruturais, que não poderão mais ser solucionadas por uma flexibilidade que no processo se perde.

Apesar de tudo, é importante preservar a saga como elemento central da identidade do país, aquela que tornou possível a sua independência. Fazê-lo é uma tarefa que está longe de ser simples ou directa. Requer a transformação do ambiente, dos actores envolvidos e da natureza da narrativa.

Em primeiro lugar, é preciso reconhecer que o acesso ao passado constitui um direito fundamental, e que as lembranças de cada um fazem parte da substância que forma a memória colectiva. Isto significa que, por mais importante que seja a luta de libertação, é apenas parte, não a totalidade, do passado comum. Em segundo lugar, que o estatuto de testemunha não constitui um privilégio. Afinal de contas, a democracia, pelo menos teoricamente, cobre de maneira igual e cega os que libertaram e os que foram libertados. E em terceiro lugar, relativizar a luta de libertação enquanto um entre vários passados significa abri-la, deixá-la respirar para além do estreito campo da política, aqui entendido como uma entre várias formas de funcionamento da sociedade, mesmo se é aquele que gere os restantes. Manter a memória da luta de libertação inteiramente confinada ao campo da política é um acto contra a democracia e contra a cultura. Por outras palavras, o presente é demasiado largo, demasiado complexo e demasiado precioso para permanecer refém de uma interpretação fechada e rígida do passado. E o novo paradigma é, já não como assegurar a unidade, mas como gerir a pluralidade de perspectivas.

Desta maneira a narrativa ficará aberta a uma multitude de outras maneiras sociais de lidar com o passado, incluindo a historiografia (que tem de reinventar a autonomia do seu campo) e, claro, a arte. 
A conjugação da falta de acesso aos arquivos e o desaparecimento das testemunhas criaria uma situação extrema na qual o passado permaneceria refém de um presente de contornos obscuros. Todavia, uma vez que o passado foi vivido por todos nós ou os nossos ancestrais, ele não tem terratenentes. O passado é uma terra sem tenentes.

Abrir os arquivos ou mantê-los longe dos olhos do público não é em si o que preservará a grande narrativa. Isso só influenciará a maneira como a fábula se vai transformar. Há que ter em conta que, sempre que os caminhos para chegar à substância do passado estão fechados, surge inevitavelmente um novo e precioso instrumento chamado imaginação. $\mathrm{Na}$ arte, tal como nas ciências sociais e humanidades, a imaginação é um instrumento fundamental para preencher o vazio criado pela negação da experiência. De facto, a ausência de evidência de arquivo ou de fontes testemunhais será sempre compensada por este poderoso mecanismo.

Paul Ricoeur diz-nos que a memória é uma província da imaginação: "É sob o signo da associação de ideias que acontece esse curto-circuito entre a memória e a imaginação: se estes dois efeitos estão ligados pela contiguidade, evocar um - ou seja, imaginar - é invocar o outro, ou seja, lembrar-se" (2000: 5). Talvez seja por isso altura de olharmos para as coisas de maneira diferente, encarando a tensão da memória política com as outras memórias como positiva e capaz de nos abrir novos caminhos. No contexto de uma experiência extrema como a da sua própria pesquisa, Beatriz Sarlo escreve que "a literatura [de ficção] não é capaz de resolver ou explicar todos os problemas que enfrentamos, mas aquele que conta uma história pensa sempre fora da experiência, como se os seres humanos além de sofrerem os seus pesadelos também pudessem apropriar-se deles" (2007: 119). Poderíamos acrescentar que tal se aplica não só aos pesadelos mas também a todas as memórias sociais fundamentais, e portanto que a literatura de ficção torna possível pensar na luta de libertação sem necessariamente a experimentar; e, por mais paradoxal que possa parecer, ao fazê-lo, ao imprimir nela uma dimensão ficcional, alimenta a fábula congelada com aquilo que, através de um debate aberto, a permite transformar-se em verdadeira memória social.

Ao falarmos do passado enfrentamos - como diria Paul Ricoeur (1984) - dois tempos distintos: o tempo daquilo que é enunciado e o tempo da enunciação, que é o presente. Assim, ao perguntarmos ao passado também estamos, de certa maneira, a fazer perguntas sobre o presente. A natureza e qualidade dessas perguntas diz muito da natureza e qualidade das nossas vidas, daquilo que somos hoje. 


\section{Referências bibliográficas}

Agamben, Giorgio (2008), Infância e história. Destruição da experiência e origem da história. Belo Horizonte: Editora UFMG.

Bragança, Aquino de; Depelchin, Jacques (1986), "Da idealização da Frelimo à compreensão da história de Moçambique, Estudos Moçambicanos, 5/6, 29-52.

Coelho, João Paulo Borges (2005), "Política e memória. Fontes arquivísticas e história contemporânea de Moçambique: Problemas e algumas perspectivas”, Actas do IV Seminário Internacional de Arquivos de Tradição Ibérica. Lisboa: Torre do Tombo, 24-28 de Outubro.

Coelho, João Paulo Borges (2007), "Memória das guerras moçambicanas", comunicação apresentada na conferência "Memórias de Guerras", Coimbra, Centro de Estudos Sociais da Universidade de Coimbra, 5 de julho [mimeo].

Coelho, João Paulo Borges (2010), "Memory, History, Fiction. A Note on the Politics of the Past in Mozambique". Comunicação apresentada nas "Journées d'étude 'Il était une fois les indépendances africaines... La fin des empires?"”. Paris: EHESS, Outubro [mimeo].

Coelho, João Paulo Borges (2013), "Politics and Contemporary History in Mozambique: A Set of Epistemological Notes”, Kronos, 39(1), 20-31.

Ginzburg, Carlo (2007), O fio e os rastros. Verdadeiro, falso, fictício. São Paulo: Companhia das Letras.

Ki-zerbo, Joseph; Mazrui, Ali A.; Wondki, Christophe (em colaboração com Boahen, A. Adu) (1993), "Nation-building and Changing Political Values", in Ali A. Mazrui (org.), Unesco General History of Africa VIII: Africa since 1935. Paris, Oxford e Berkeley: UNESCO, Heinemann e University of California Press, 468-498.

Ricoeur, Paul (1984), Temps et récit 2. Paris: Seuil.

Ricoeur, Paul (2000), La mémoire, l'bistoire, l'oubli. Paris: Seuil.

Sarlo, Beatriz (2007), Tempo passado. Cultura da memória e guinada subjectiva. São Paulo: Companhia das Letras/Editora UFMG.

Todorov, Tzvetan (2004), Les abus de la mémoire. Paris: Arléa.

Znepolski, Vaylo (2001), "Les malheurs de l'histoire du temps présent: Usages postcommunistes de la mémoire", Divinatio, 13, 73-90.

Artigo recebido a 11.09.2014

Aprovado para publicação a 22.12.2014

\section{João Paulo Borges Coelho}

Departamento de História, Faculdade de Letras e Ciências Sociais, Universidade Eduardo Mondlane Campus Universitario Principa, Maputo, C. P. 257, Moçambique

Contacto: jp.borgescoelho@gmail.com 
